\title{
Angle Class II, division 2 malocclusion with severe overbite and pronounced discrepancy*
}

\author{
Daniela Kimaid Schroeder**
}

\begin{abstract}
This article reports the treatment of a young patient at 13.8 years of age who presented with an Angle Class II, division 2 malocclusion, prolonged retention of deciduous teeth, dental crossbite and severe overbite, among other abnormalities. At first, the approach involved rapid maxillary expansion followed by the use of Kloehn headgear and fixed orthodontic appliance. Treatment results demonstrate the importance of careful diagnosis and planning as well as the need for patient compliance during treatment. This case was presented to the Brazilian Board of Orthodontics and Facial Orthopedics (BBO). It is representative of the free category and fulfills part of the requirements for obtaining the BBO Diploma.
\end{abstract}

Keywords: Class II, division 2. Crossbite. Severe overbite. Prolonged retention of deciduous teeth.

\section{HISTORY AND ETIOLOGY}

The patient sought orthodontic treatment at 13.8 years of age. Her main complaint was the fact that her teeth took too long to fall and she was ashamed to smile. No significant information was found in her past medical and dental records. Her malocclusion, mainly presented lack of space for the alignment of certain teeth, which compromised her facial aesthetics significantly (Fig 1), and had as major etiological factor the prolonged retention of deciduous teeth. Her menarche had occurred at age 12 .

\section{DIAGNOSIS}

Her dental pattern (Fig 1, 2) was an Angle Class II, division 2, right subdivision, excessively upright upper and lower incisors, severe deep bite (100\%), upper and lower midlines shifted $3 \mathrm{~mm}$ to the right, lack of space for eruption of tooth 13 and alignment of other teeth, dental crossbites and atretic arches.

She displayed skeletal harmony, with ANB equal to $4^{\circ}$, and adequate maxillary and mandibular positioning. As mentioned, the upper and lower incisors were excessively upright with 

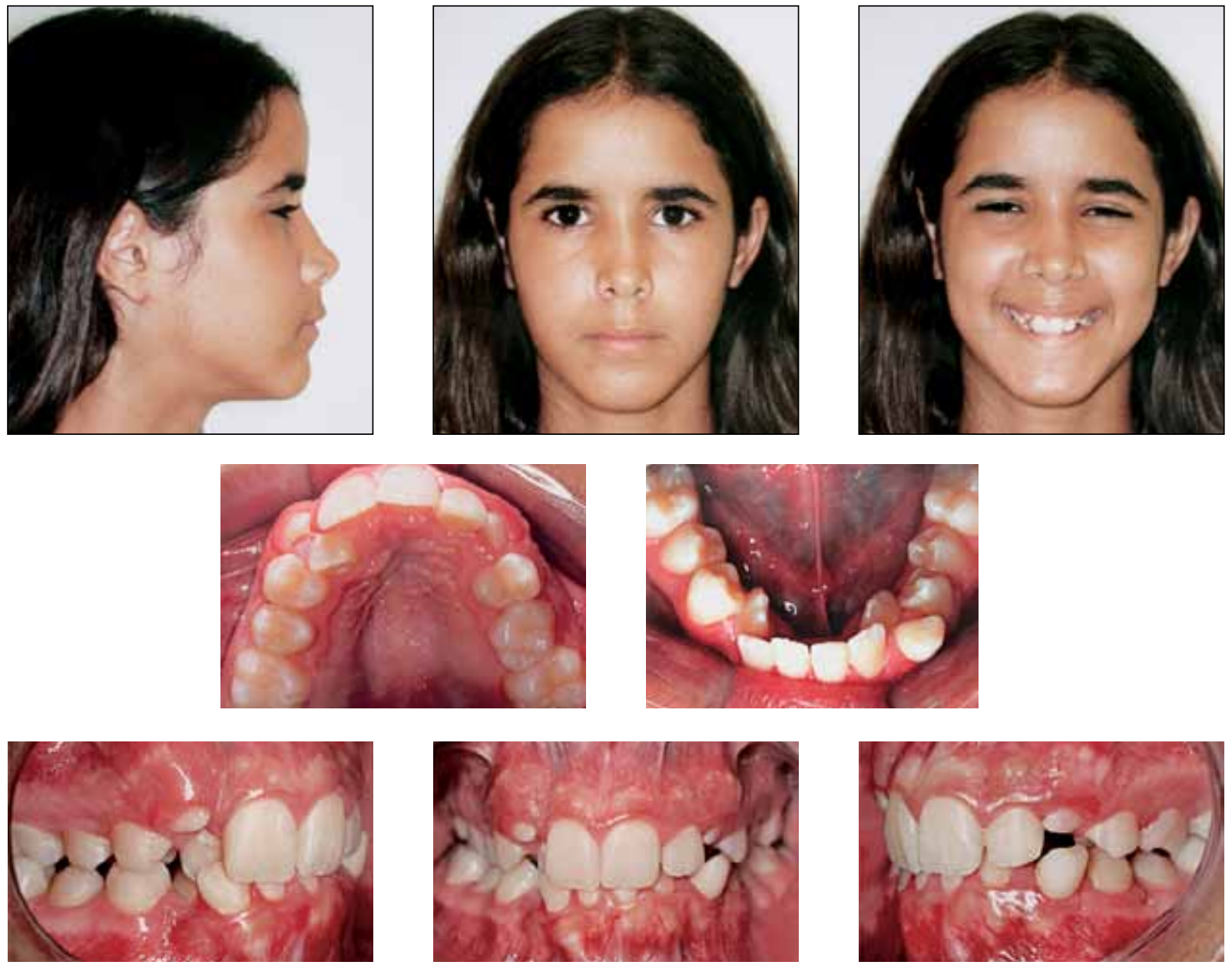

FIGURE 1 - Initial facial and intraoral photographs.
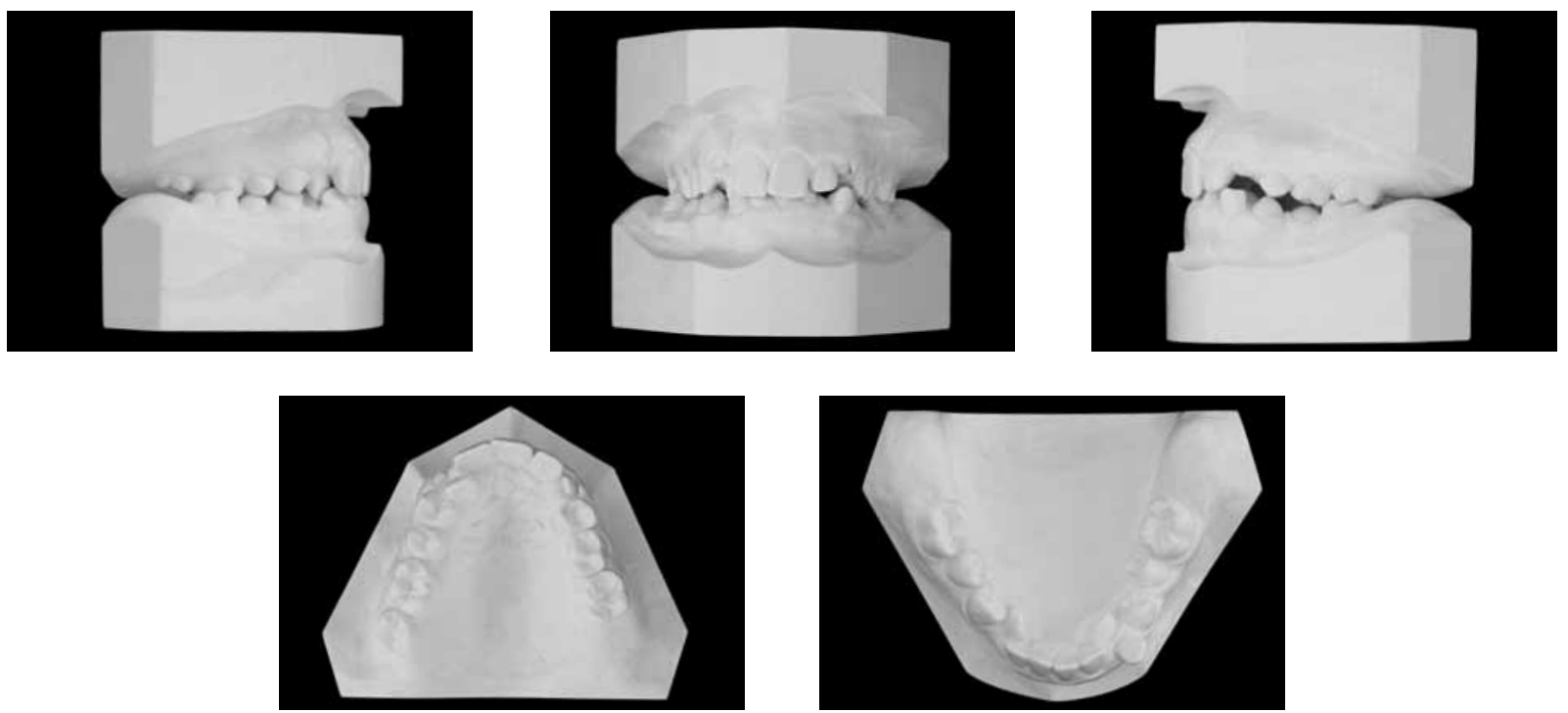

FIGURE 2 - Initial dental casts. 
an interincisal angle of $157^{\circ}$, IMPA of $75^{\circ}, 1$-NA of $7^{\circ}$ and $2.5 \mathrm{~mm}$, and $1-\mathrm{NB}$ of $12^{\circ}$ and $4 \mathrm{~mm}$. These features can be seen in figure 4 and table 1 .

An analysis of the periapical and panoramic radiographs (Fig 3) reassured that the patient did not present with any condition that might compromise her orthodontic treatment.

The patient had a slightly convex profile and an unpleasant smile due to crowding and incorrect tooth inclinations (Figs 1 and 4).

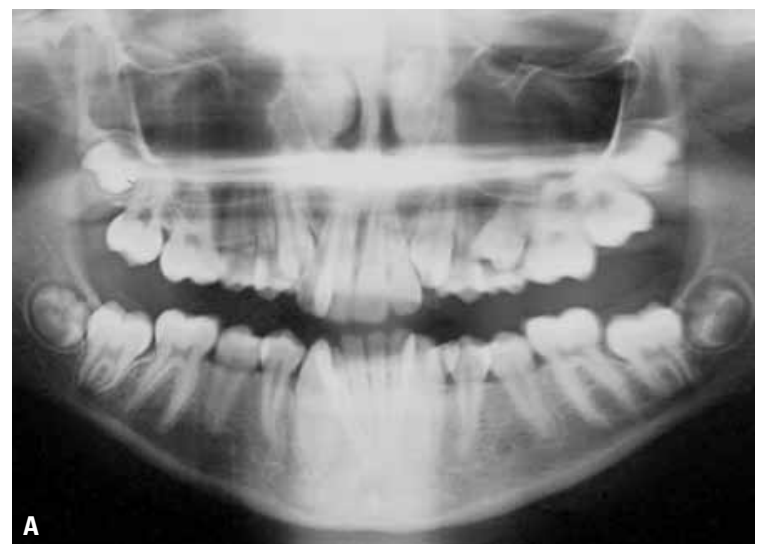

FIGURE 3 - Initial panoramic (A) and periapical (B) radiographs.

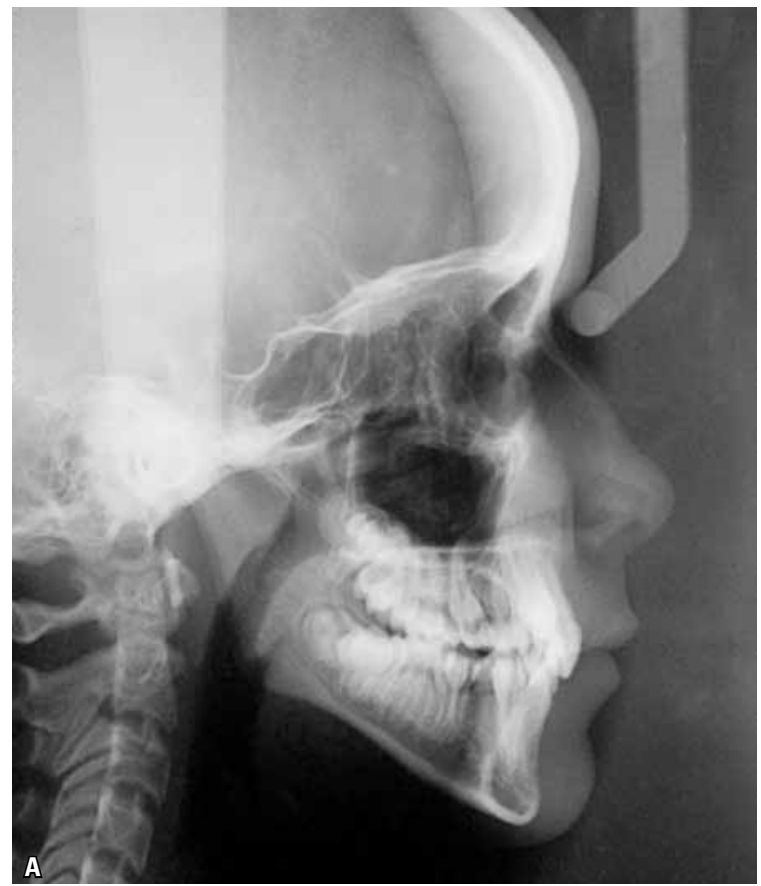

\section{TREATMENT GOALS}

In the anteroposterior direction, the aim was to establish an Angle Class I relationship and improve upper and lower incisor inclination. In the vertical direction, it would be necessary to reduce the severe overbite by leveling the upper and lower arches. In the transverse direction, upper and lower arch expansion was performed to increase intercanine width.
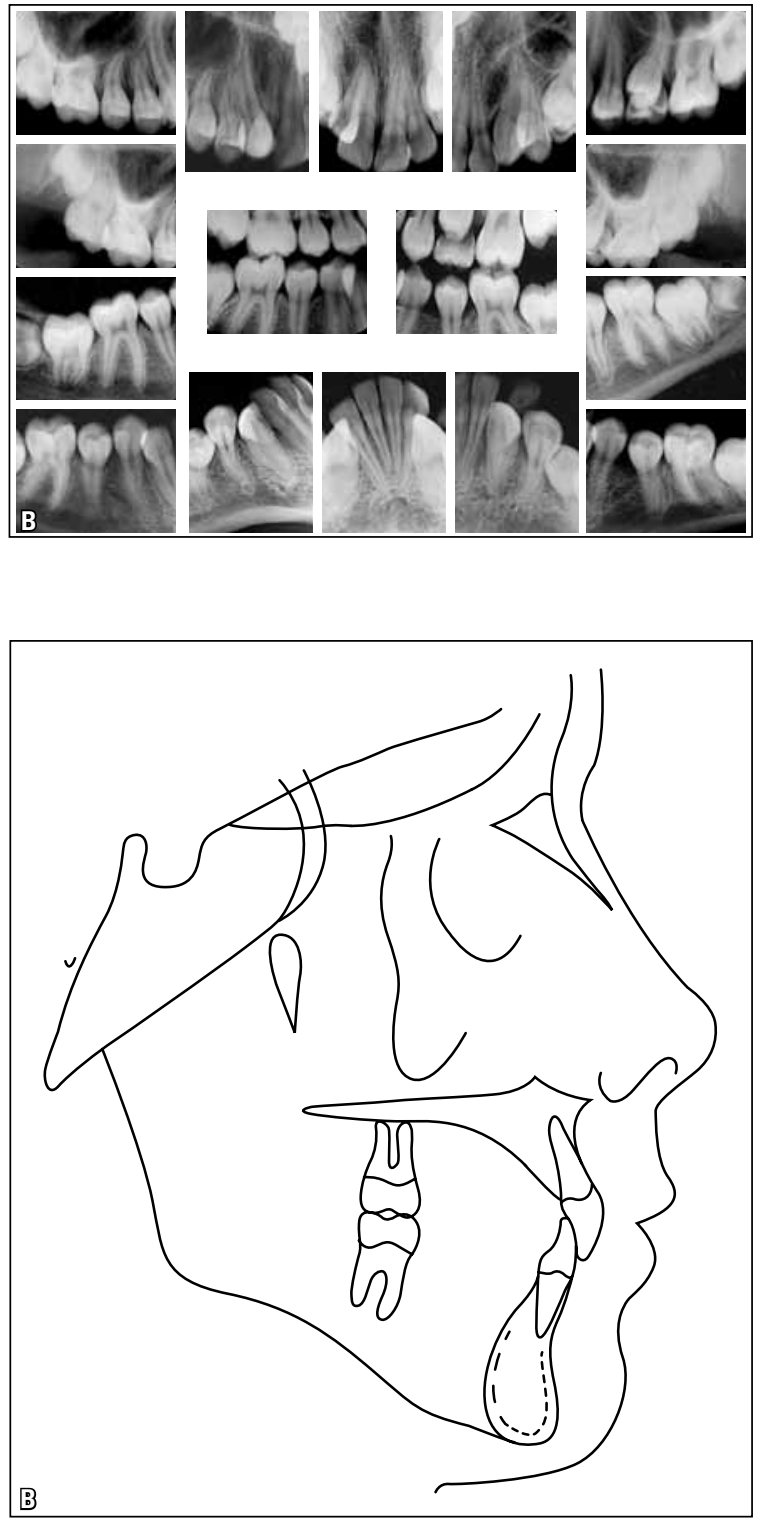

FIGURE 4 - Initial profile cephalometric radiograph (A) and cephalometric tracing (B). 
With this, it was expected that crossbites would be eliminated, and adequate overbite and upper and lower midline correction would be achieved, significantly improving smile aesthetics.

\section{TREATMENT PLAN}

A treatment plan was established, starting with palatal expansion to increase the transverse maxillary dimension and make room for tooth alignment.

After removing the expansion appliance, an asymmetric Kloehn headgear (AKHG) would be used with the purpose of correcting the molar relationship and creating space. Concurrently with the AKHG, upper orthodontic appliance would be installed, alignment and leveling started in this arch, and only when the amount of overbite permited, the lower orthodontic appliance would be bonded. To improve the form of the lower arch and make room for alignment and leveling of the lower teeth, the plan was to use archwires featuring greater intercanine width, since the canine lingual inclination and an atretic arch would allow such expansion.

To assist in opening space for tooth 13 and thus correct the upper midline, a compressed open spring would be placed between teeth 12 and 14, starting from the 0.018-in archwire.

To finish the case, the use of upper and lower $0.019 \times 0.025$-in archwires would be coordinated, with first and third order bends, and individualized intermaxillary elastic mechanics would be applied, according to the needs of this particular case.

After the active treatment phase, an upper wraparound-type retention plate would be used and, in the lower arch, a 0.028-in intercanine arch.

\section{TREATMENT PROGRESS}

To expand the palate a modified Haas appliance was employed with activation of 2/4 turn of the screw once a day. The same appliance was used as a retainer for 6 months. The maxilla was expanded, which enhanced the form of the upper arch and consequently of the lower arch.

After removing the expansion screw, the asymmetric AKHG was adjusted by keeping its external right arm longer and open, with a force of $350 \mathrm{~g}$, to be worn for approximately 14 hours/ day. This corrected the molar relationship and helped to make space for upper tooth alignment.

Slot $0.022 \times 0.028$-in standard edgewise metal brackets with no torques or angulations were used. The orthodontic appliance was initially installed on the upper arch. It was only after adequate space and height had been achieved that the lower arch appliance was bonded.

On the upper arch, 0.014-in to 0.020-in archwires were used for alignment and leveling and from the moment that 0.018-in archwires began to be used, an open spring was compressed between teeth 12 and 14 to help create space for positioning tooth 13 and subsequent midline correction. After alignment and leveling of all teeth, individualized $0.019 \times 0.025$ in stainless steel archwires were inserted on the upper arch to finish the case.

The same alignment and leveling procedures used for the upper arch were also performed on the lower, although the archwires were contoured in order to expand the lower arch by uprighting the canines and premolars and allowing protrusion of the incisors, which were retroclined before treatment. This enabled a correct alignment, leveling and midline correction. To finish the case, a $0.019 \times 0.025$-in stainless steel archwire with custom-made bends was used.

After ensuring that all the intended goals had been achieved, the fixed orthodontic appliance was removed and the retention phase begun. An upper wraparound-type retention plate and an 0.028-in stainless steel lower intercanine arch were used. The patient was instructed to wear the retainer plate full time during the first six months and then only for nighttime use. 
The patient had her upper and lower third molars extracted.

\section{TREATMENT RESULTS}

In reviewing the patient's final records, it became clear that the major goals set at the beginning of treatment were attained (Figs 5, 6, 8). In the maxilla, ANB was reduced by $2^{\circ}$ and the position of the maxilla relative to the overall profile improved considerably, reducing the angle of convexity from $8^{\circ}$ to $1^{\circ}$. In addition, there was adequate vertical control and considerable enhancement of the upper arch form (Figs 5, 6, 8).
The teeth exhibited adequate alignment and improved incisor inclination. The overbite was also corrected and intercanine width increased by 11 $\mathrm{mm}$, as initially planned, while the intermolar width was maintained.

In the mandible, a clockwise rotation occurred as the FMA angle (Tweed) increased from $28^{\circ}$ to $32^{\circ}$ (Figs 8,9 and Table 1 ) due to the use of the headgear as well as leveling. From a dental standpoint, adequate alignment was achieved, the curve of Spee was leveled and the incisors were protruded with an increase in the IMPA angle (Tweed) from $75^{\circ}$ to $90^{\circ}$ (Figs 8, 9 and Table 1).
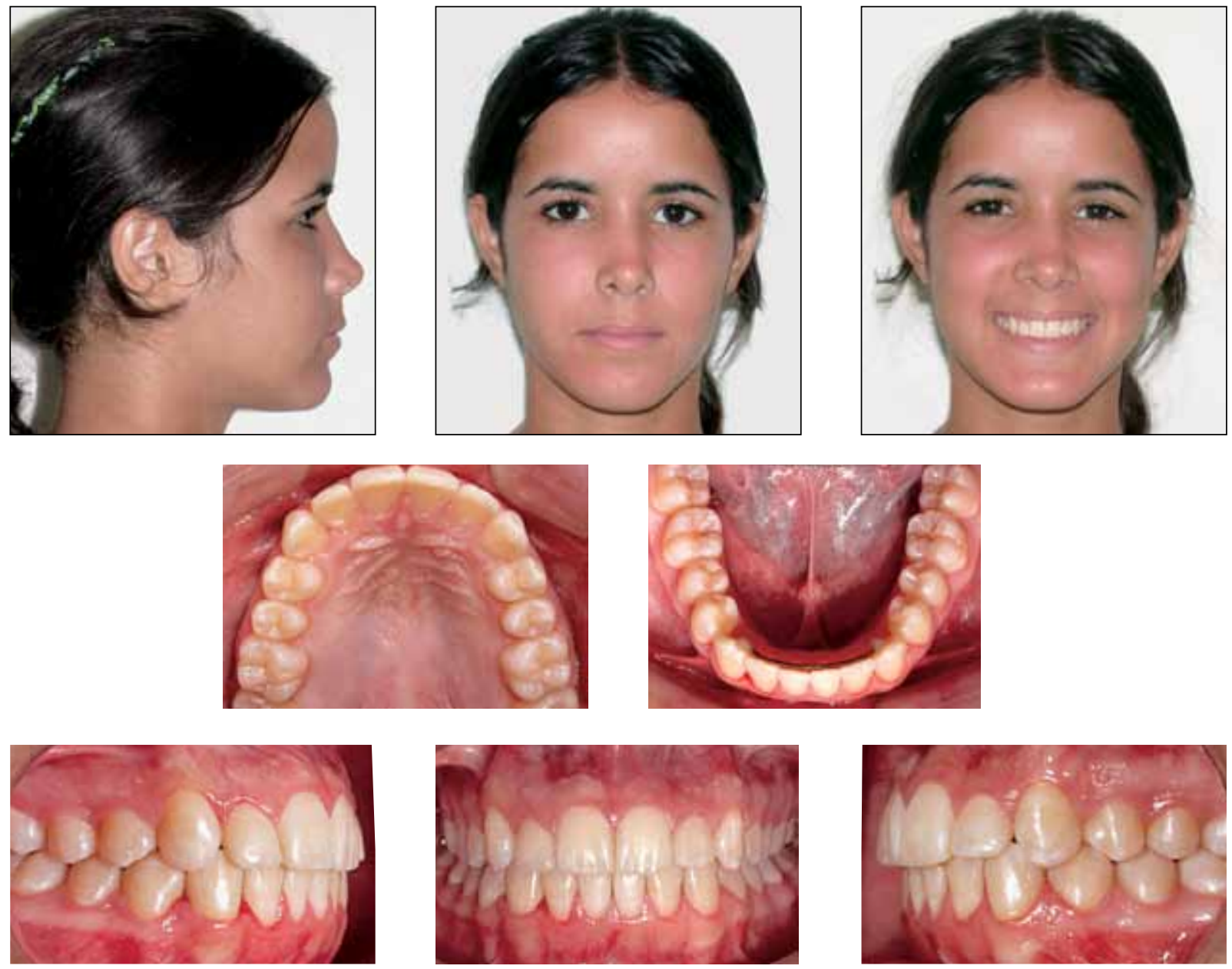

FIGURE 5 - Final facial and intraoral photographs 

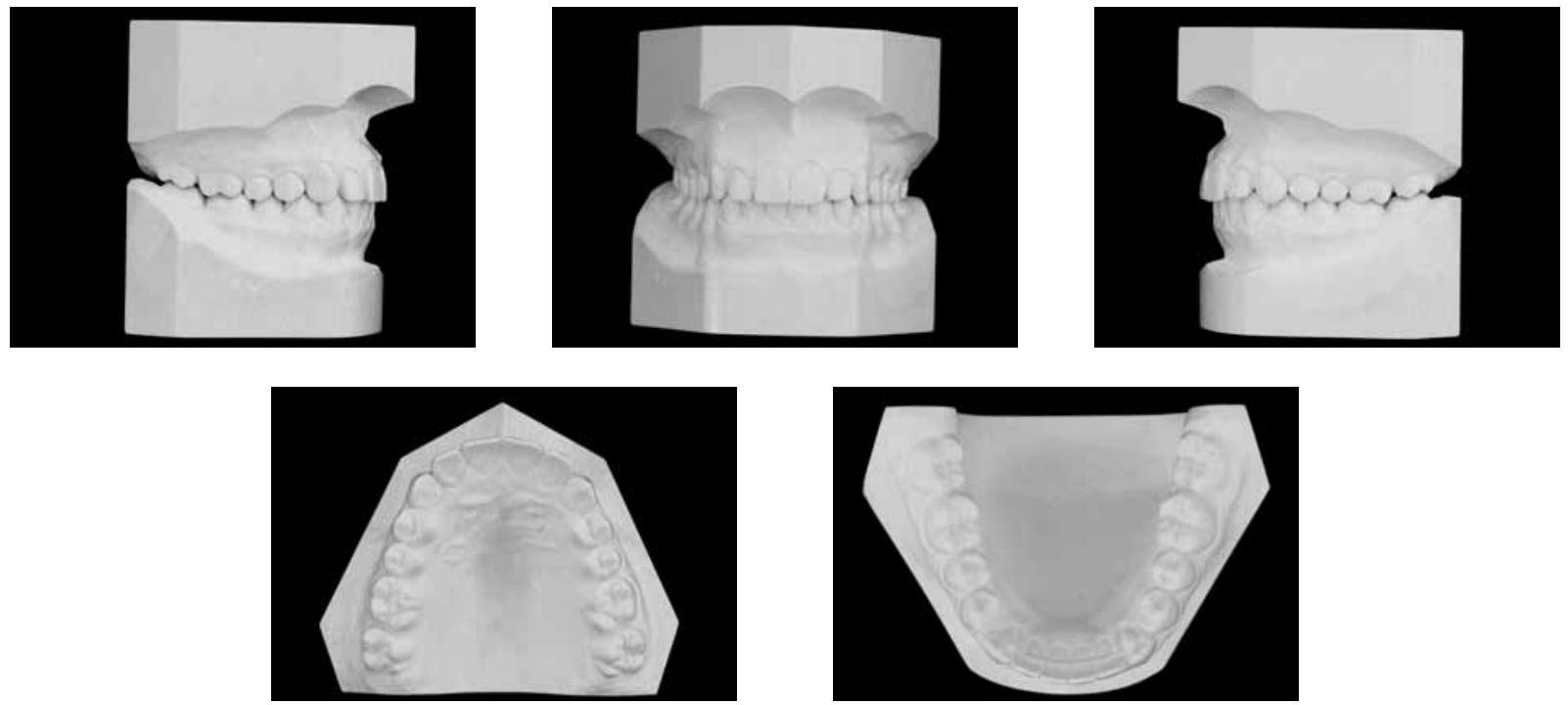

FIGURE 6 - Final casts.
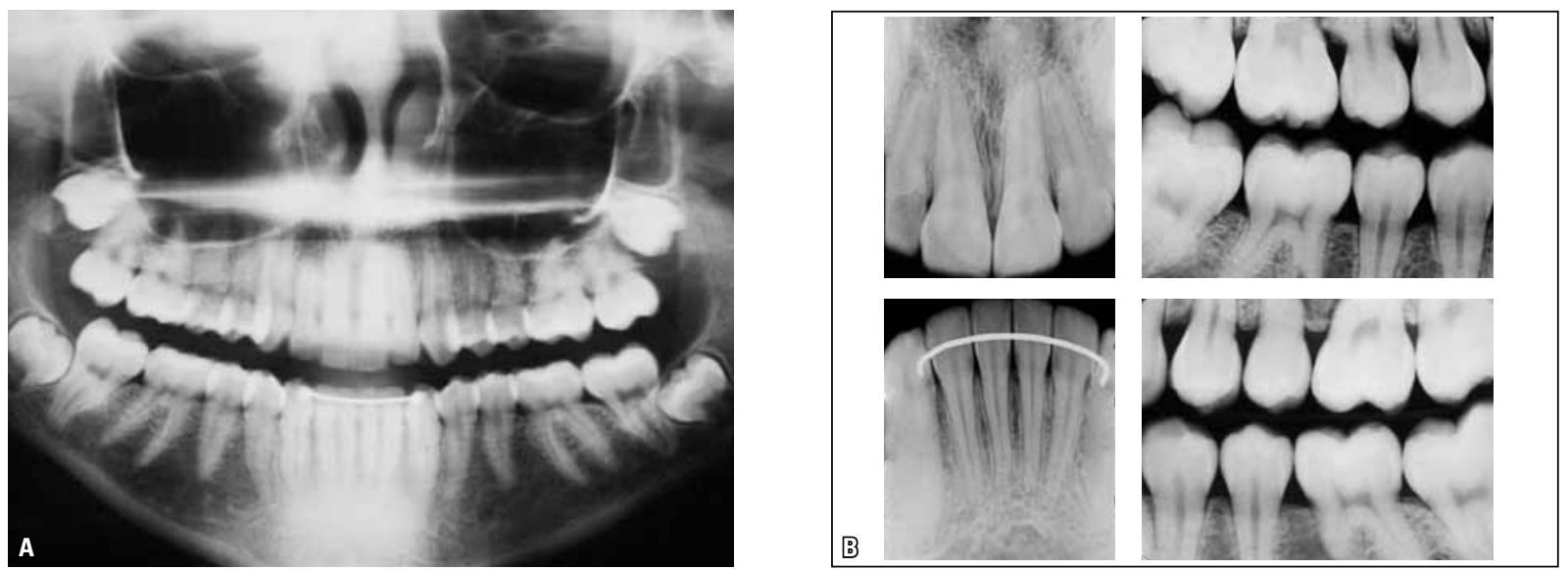

FIGURE 7 - Final panoramic (A) and interproximal periapical (B) radiographs.

Regarding occlusion, the dental midlines were coincident to the facial midline, the molars and canines came into normal occlusion, vertical overbite became appropriate and disocclusion guides satisfactory.

The panoramic radiograph (Fig 7A) revealed adequate root parallelism. The gentle rounding of the apices of the upper incisor roots observed in the Figure 7B is compatible with the amount of movement produced. The profile cephalometric radiograph (Fig 8A) shows improved overbite and interlabial relationship.

Due to the correction of the asymmetries and severe overbite, a significant improvement in smile aesthetics was achieved, which also benefited the patient's face (Fig 5). 

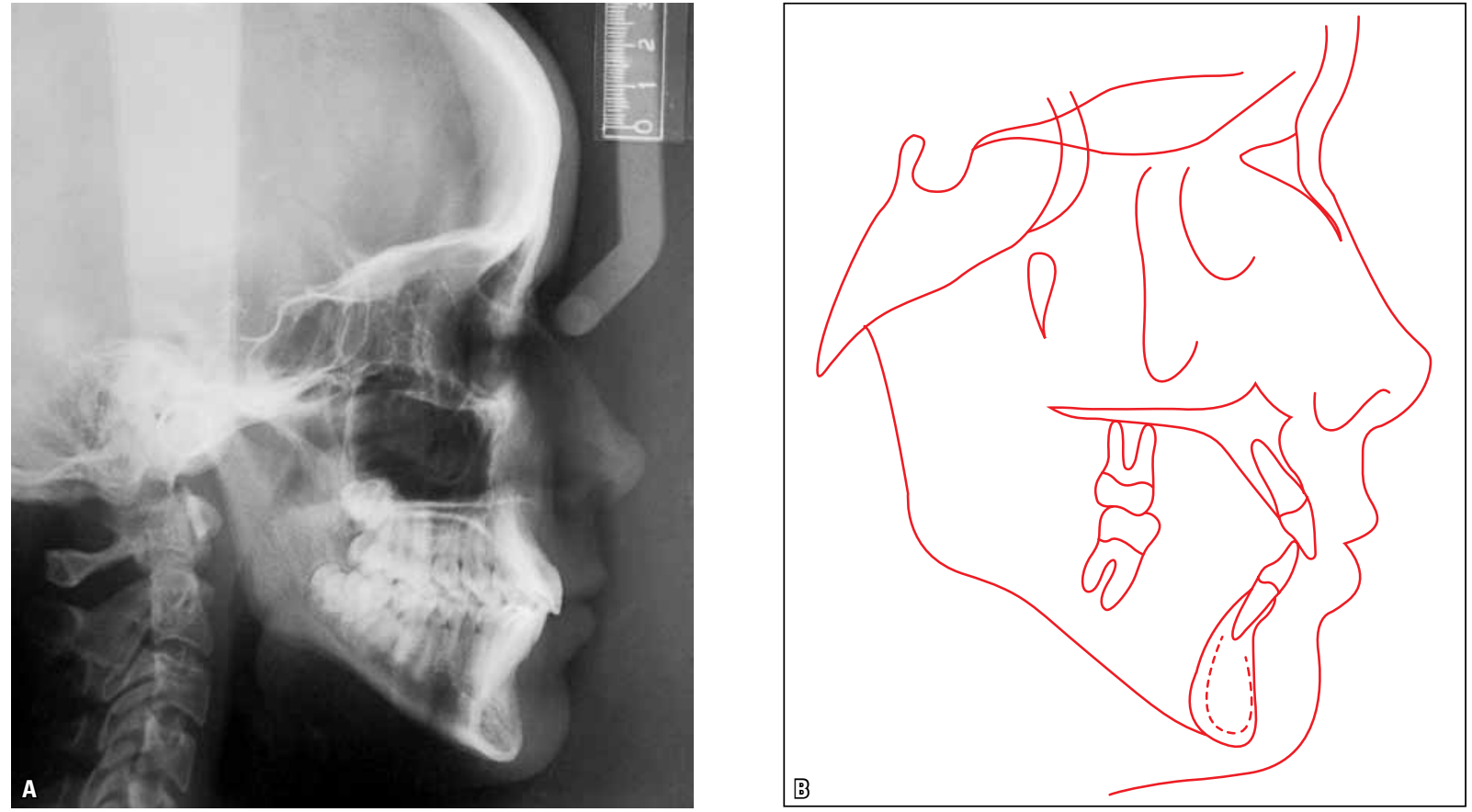

FIGURE 8 - Final profile cephalometric radiograph (A) and cephalometric tracing (B).
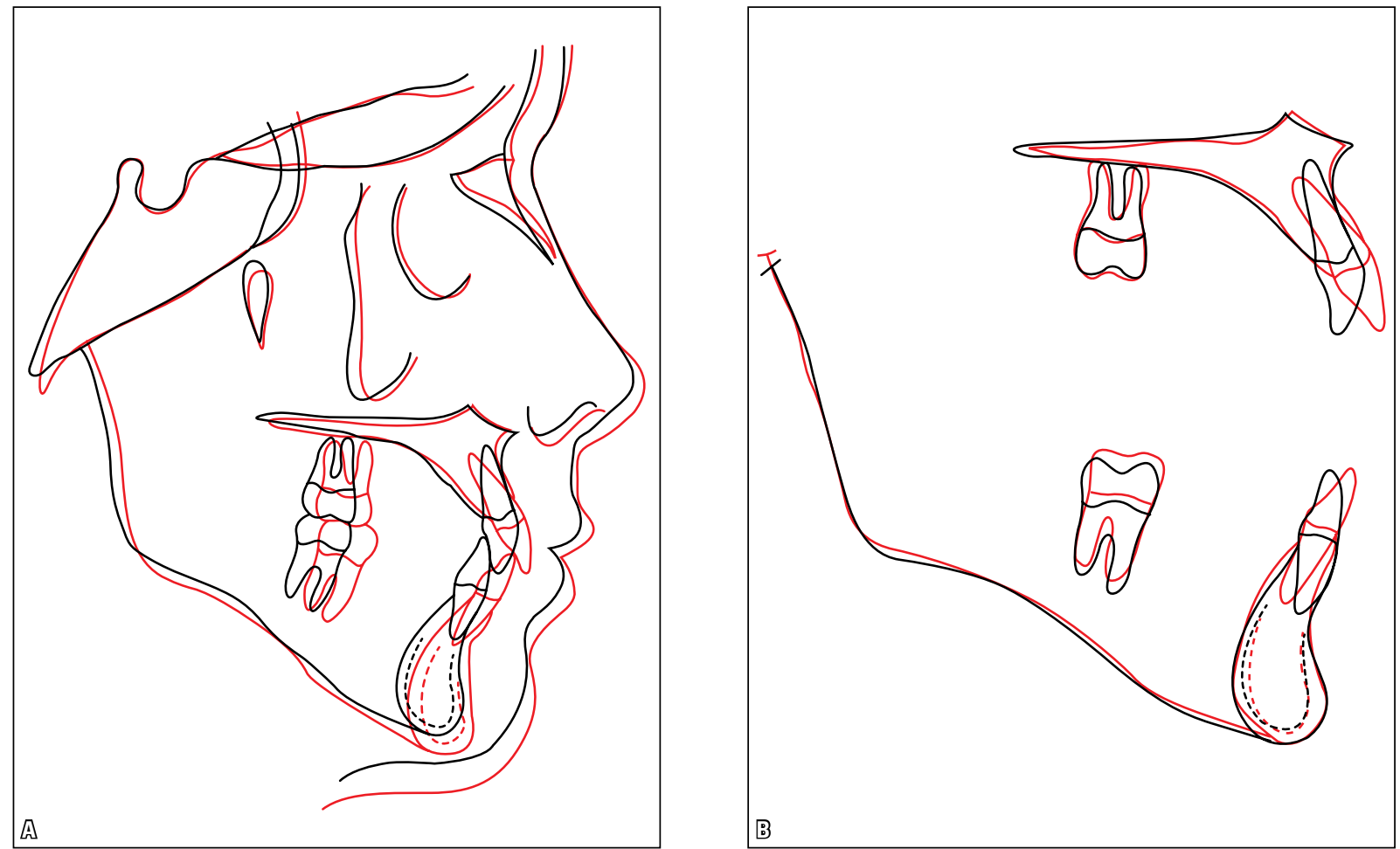

FIGURE 9 - Total (A) and partial (B) superimposition of initial (black) and final (red) cephalometric tracing. 
TABLE 1 - Summary of cephalometric measurements.

\begin{tabular}{|c|c|c|c|c|c|}
\hline & MEASUREMENTS & Normal & $\mathbf{A}$ & B & $\begin{array}{l}\text { DIFERENCE } \\
\text { A-B }\end{array}$ \\
\hline \multirow{9}{*}{ 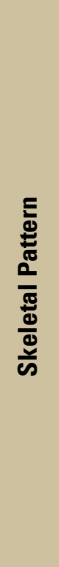 } & SNA (Steiner) & $82^{\circ}$ & $84^{\circ}$ & $82^{\circ}$ & 2 \\
\hline & SNB (Steiner) & $80^{\circ}$ & $80^{\circ}$ & $80^{\circ}$ & 0 \\
\hline & ANB (Steiner) & $2^{\circ}$ & $4^{\circ}$ & $2^{\circ}$ & 2 \\
\hline & Convexity Angle (Downs) & $0^{\circ}$ & $8^{\circ}$ & $1^{\circ}$ & 7 \\
\hline & $Y$ axis (Downs) & $59^{\circ}$ & $59^{\circ}$ & $63^{\circ}$ & 4 \\
\hline & Facial Angle (Downs) & $87^{\circ}$ & $89^{\circ}$ & $86^{\circ}$ & 3 \\
\hline & SN - GoGn (Steiner) & $32^{\circ}$ & $34^{\circ}$ & $36^{\circ}$ & 2 \\
\hline & FMA (Tweed) & $25^{\circ}$ & $29^{\circ}$ & $32^{\circ}$ & 3 \\
\hline & IMPA (Tweed) & $90^{\circ}$ & $75^{\circ}$ & $90^{\circ}$ & 15 \\
\hline \multirow{5}{*}{ 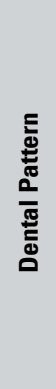 } & $\underline{1}$ - NA (degrees) (Steiner) & $22^{\circ}$ & $7^{\circ}$ & $28^{\circ}$ & 21 \\
\hline & $\underline{1}-\mathrm{NA}(\mathrm{mm})$ (Steiner) & $4 \mathrm{~mm}$ & $2.5 \mathrm{~mm}$ & $8 \mathrm{~mm}$ & 5.5 \\
\hline & $\overline{1}-\mathrm{NB}$ (degrees) (Steiner) & $25^{\circ}$ & $12^{\circ}$ & $28^{\circ}$ & 16 \\
\hline & $\overline{1}-\mathrm{NB}(\mathrm{mm})$ (Steiner) & $4 \mathrm{~mm}$ & $4 \mathrm{~mm}$ & $7 \mathrm{~mm}$ & 3 \\
\hline & $\frac{1}{1}$ - Interincisal angle (Downs) & $130^{\circ}$ & $157^{\circ}$ & $121^{\circ}$ & 36 \\
\hline \multirow{3}{*}{ 車 } & $\overline{1}-\mathrm{APo}(\mathrm{mm})$ (Ricketts) & $1 \mathrm{~mm}$ & $1.5 \mathrm{~mm}$ & $5 \mathrm{~mm}$ & 3.5 \\
\hline & Upper Lip - S Line (Steiner) & $0 \mathrm{~mm}$ & $2 \mathrm{~mm}$ & $1 \mathrm{~mm}$ & 1 \\
\hline & Lower Lip - S Line (Steiner) & $0 \mathrm{~mm}$ & $1 \mathrm{~mm}$ & $1 \mathrm{~mm}$ & 0 \\
\hline
\end{tabular}

\section{FINAL CONSIDERATIONS}

At first, the possibility of treating this case with tooth extractions was raised due to an apparent lack of space for the upper and lower teeth. However, the lack of space was the result of altered axial inclinations, tooth migration and atresia of the dental arches. The patient's age allowed these problems to be corrected using orthodontic resources, whereby space was created without compromising periodontal support, esthetics and function. ${ }^{2,3,4,5}$ Stability is yet another factor that should be taken into account when protruding teeth and expanding dental arches. It is believed that because intercanine distances were widened by correcting upper and lower canine position and not by bringing the teeth out of their bone bases, it is highly likely that stability will be maintained after correction. ${ }^{1}$ Even so, retention was carefully planned and half-yearly follow-up visits scheduled.

Treatment was expected to take up 30 months. However, the patient had to relocate 
to another town for two years, for educational purposes. During this period, she missed too many appointments, significantly increasing treatment time to 48 months.

The patient's compliance in wearing the headgear was unstable, alternating moments

\section{REFERENCES}

1. Giannely A. Evidence-based therapy: an orthodontic dilemma. Am J Orthod Dentofacial Orthop. 2006 May;129(5):596-8.

2. Haas AJ. Palatal expansion: just the beginning of dentofacial orthopedics. Am J Orthod. 1970 Mar;57(3):219-55.

3. Haas AJ. Long-term post-treatment evaluation of rapid palatal expansion. Angle Orthod. 1980 Jul;50(3):189-217. of total collaboration with others of sheer negligence, despite our constant reminders and encouragement. As can be seen in the final records, the overall result was considered adequate in terms of occlusion and facial and dental aesthetics.
4. Hershey H, Houghton CW, Burstone CJ. Unilateral face-bows: a theoretical and laboratory analysis. Am J Orthod. 1981 Mar;79(3):229-49.

5. Turpin DL. Correcting the Class II subdivision malocclusion. Am J Orthod Dentofacial Orthop. 2005 Nov;128(5):555-6.
Submitted: March 2010

Revised and accepted: April 2010

Contact address

Daniela Kimaid Schroeder

Rua Visconde de Pirajá, 444, sala 205 - Ipanema

CEP: 22.410-002 - Rio de Janeiro/RJ, Brazil

E-mail: danikimsc@gmail.com 